\title{
Bioética em reprodução humana assistida: influência dos fatores sócio-econômico- culturais sobre a formulação das legislações e guias de referência no Brasil e em outras nações
}

| ${ }^{1}$ Tatiana Henriques Leite, ${ }^{2}$ Rodrigo Arruda de Holanda Henriques |

Resumo: Em 1978 nasceu oprimeiro bebê gerado por fertilização in vitro (FIV). A partir de então, as técnicas de reprodução assistida (TRA) começaram a se desenvolver e se transformar em uma realidade clínica no tratamento da infertilidade. No entanto, a reprodução assistida fez surgir grandes polêmicas de caráter moral e ético. Devido a essas divergências, alguns países optaram por regulamentar a reprodução assistida através de legislações específicas ou guias de referência. $\mathrm{O}$ objetivo deste trabalho é comparar as legislações ou guias de referências em reprodução humana assistida de diferentes países; mostrar as diferenças em relação às normatizaçóes em TRA, levando em consideração aspectos sociais, financeiros, religiosos e culturais de nove países: Brasil, China, Egito, Índia (países com guia de referência) e Dinamarca, Israel, Itália, África do Sul, e Espanha (países com legislação específica). Foi realizada revisão da literatura entre 2006 e 2011, nos sites de buscas Cochrane BVS e PUB MED. Alguns documentos importantes referentes ao assunto foram adicionados à pesquisa. Os itens avaliados foram: existência de leis ou guias de referência para TRA, religião predominante em cada país, número de centros que realizam TRA, existência de cobertura por plano de saúde ou assistência do governo para TRA, necessidade de estado civil e acesso de pessoas solteiras e casais homoafetivos, número de embriōes transferidos, criopreservação e doações de gametas e embriōes, redução embrionária, PGD, seleção de sexo por motivos não médicos, útero de substituição; status do embriāo. Foram encontradas grandes divergências entre os países, das quais muitas são determinadas pela religião.

\author{
1 Graduação em Biomedicina; \\ especialização em Reprodução \\ Humana Assistida; mestranda \\ em Saúde Coletiva no IMS/ \\ UERJ. Rio de Janeiro, Brasil. \\ Endereço eletrônico: henriques. \\ tatiana@gmail.com \\ 2 Graduação em Direito; \\ docente da UNESA. Rio de \\ Janeiro, Brasil. Endereço \\ eletrônico: holanda_rodrigo@ \\ hotmail.com
}




\section{Introdução}

Em 25 de julho de 1978, nasceu Louise Brown, primeiro bebê gerado por fertilização in vitro (FIV) (STEPTOE; EDWARDS, 1978). A partir daí, as técnicas de reprodução assistida (TRA) começaram a se desenvolver e se transformar em realidade clínica no tratamento da infertilidade. Contudo, alguns conflitos começaram a surgir e a questionar a licitude moral e ética dos procedimentos realizados. Questóes referentes ao status moral do embrião, descarte, abandono e doações de gametas e embriōes, utilização do diagnóstico genético pré-implantacional (PGD), seleção de sexo embrionário, útero de substituição, reprodução póstuma e redução embrionária são os principais embates que surgiram com a utilização dessa tecnologia.

O status moral do embrião é a questão mais antiga em pauta relacionada à reprodução humana assistida. É controverso o momento exato em que a vida se inicia. Dessa forma, não há consenso se o embriāo é uma vida humana e deve ser tratada como tal, ou não. A Sociedade Americana de Medicina Reprodutiva (ASRM) propõe que o embrião deve ser considerado uma vida em potencial e por isso deve ter status especial em relação a outros tecidos do organismo, mas isso não justifica ser visto e protegido como uma pessoa (ETHICS COMMITTEE OF ASRM, 2009). Alguns grupos religiosos têm uma posição mais conservadora. Eles acreditam que a vida humana se origina no momento em que ocorre a fecundação e por isso o embrião deve ser considerado uma vida humana em desenvolvimento, tendo todos os direitos garantidos, inclusive o direito à vida (DONUM VITAE, 1983).

Com base nesse conceito mais conservador sobre o status do embrião, inserese a controvérsia gerada em relação ao procedimento de redução embrionária. Em tratamentos de reprodução assistida, gravidezes múltiplas são de certa forma frequentes devido à transferência de múltiplos embriōes para o útero materno. No entanto, seja por motivos médicos ou por desejo do casal, é possível reduzir o número de fetos a serem gerados através da redução embrionária. O procedimento consiste em eliminar alguns embriōes, normalmente os menos viáveis ou com localização pouco favorável dentro do útero, e dar continuidade à gravidez. Esse procedimento é discutível por se assemelhar ao aborto e ter as mesmas questôes éticas e morais envolvidas. 
Em 1983, Trounson e Mohr conseguiram a primeira gestação através da criopreservação de embriôes humanos. A partir desse feito, o congelamento de gametas e embriōes começou a ser empregado na reprodução assistida com o objetivo principal de evitar submeter a mulher a sucessivas aspirações foliculares (procedimento realizado para captação de oócitos). Uma vez que o casal definiu que a família está completa, existem, em teoria, quatro possibilidades no que diz respeito ao destino dos embriōes excedentes que estão criopreservados. As opções incluem mantê-los criopreservados indefinidamente, doar para pesquisa, doar para outro casal tentar uma gravidez ou descartar o embrião. No entanto, em muitos casos, o casal não atualiza o contato telefônico ou residencial e deixa de cumprir com suas obrigações financeiras referentes ao serviço prestado, caracterizando, assim, o abandono dos embriōes (BRANDON et al., 2005). Tentando solucionar essa adversidade, em 1996 foi realizada na Inglaterra a maior destruição de embriōes abandonados até então. $\mathrm{O}$ evento foi considerado genocídio pela Igreja católica e suscitou um debate mundial sobre o tema envolvendo a comunidade científica, civil, religiosa e política (SABBATINI,1998).

O congelamento de gametas e embriōes também tornou viável a reprodução póstuma. Sendo assim, em casos de falecimento é possível que o cônjuge remanescente possa exercer a parentalidade mesmo após a perda de um membro do par. Os questionamentos que surgem com essa possibilidade é em relação à motivação em gerar o descendente. Em muitos casos, a razão principal pode ser a dificuldade de superar ou luto e até mesmo para obter compensação financeira em partilha de herança (ETHICS COMMITTEE OF ASRM, 2004). Os casos mais comuns são quando o falecimento é do cônjuge masculino. No caso de falecimento do cônjuge feminino, é necessário que a reprodução póstuma seja realizada através do útero de substituição (situação conhecida popularmente como "barriga de aluguel").

O útero de substituição é geralmente utilizado por mulheres com alterações anatômicas no útero ou em caso de contraindicação clínica de gravidez. Mais recentemente, também tem sido utilizado por casais homoafetivos masculinos e reprodução póstuma. Em relação a esse procedimento, as questôes mais discutidas são em torno da escolha da doadora de útero, o vínculo desta com o casal que está requerendo a gravidez e se deve ocorrer compensação financeira pela cessão temporária de útero (ETHICS COMMITTEE OF ASRM, 2003). 
A doação de gametas e embriōes é procedimento normalmente utilizado quando há ausência, baixa qualidade ou problemas genéticos relacionados aos gametas ou embriōes dos progenitores. As questões debatidas em relação às doações são em referência a definição do doador genético (desconhecidos, membros da família, amigos, banco de gametas e embriōes), a ocorrência de compensação financeira e o anonimato do doador genético (ETHICS COMMITTEE OF ASRM, 2003).

O PGD (diagnóstico genético pré-implantacional) é um procedimento em que uma célula do embriāo é retirada e submetida a uma análise genética. $\mathrm{O}$ procedimento é realizado com o objetivo de selecionar e transferir embrióes sem anomalias genéticas para o útero materno. Porém esse procedimento viabiliza a seleção de sexo do embrião que é justificada quando utilizada para evitar transtornos genéticos ligados ao sexo. Porém, a seleção de sexo também pode ser feita com o objetivo exclusivo de balanço familiar. Independentemente do motivo utilizado para a realização da seleção de sexo embrionário, algumas questôes como o destino dos embriões do sexo indesejado e a possível utilização do PGD como ferramentas de eugenia são as questões mais debatidas nesse contexto (ETHICS COMMITTEE OF ASRM, 1999).

Diante do apresentado e na falta de um consenso natural em relação aos problemas éticos que surgiram com a prática da reprodução assistida, em muitos países teve início a normatização da reprodução assistida através de leis ou guia de referência. Nesse cenário, em 1984, a Austrália foi o primeiro país a propor uma legislação para o funcionamento de TRA (IFFs, 2010). Em 1987, a Igreja católica foi a primeira religião a se manifestar e declarou todos os procedimentos em reprodução assistida ilícitos, através do documento Donum Vitae.

Em 2010, a International Federation of Fertility Societies fez uma pesquisa sobre presença ou ausência de legislação específica para reprodução assistida envolvendo 103 países. Dentre eles, 42 (40,7\%) responderam existir legislação específica, $26(25,2 \%)$ possuem guias de referências ou leis não específicas (resoluções, recomendações, situações previstas na Constituição, que abrangem ou são adaptáveis à reprodução assistida e leis inespecíficas à reprodução assistida, mas que modulam sua prática de alguma forma) e 35 países (35\%) operam sem nenhuma lei ou instrução (IFFS, 2010). 
A regulamentação da reprodução humana assistida é importante para definir quais tratamentos podem ser utilizados, as modalidades de aplicação, assegurar o bem-estar dos pacientes e de todas as pessoas envolvidas com o tratamento, impondo limites quanto ao avanço científico. Isto posto, o objetivo deste trabalho é expor o cenário de diferentes países em relação às normatizações de TRA, levando em consideração aspectos sociais, econômicos, religiosos e culturais de nove países: Brasil, China, Dinamarca, Egito, Índia, Israel, Itália, África do Sul e Espanha.

\section{Materiais e métodos}

Foi realizada uma revisão da literatura de 2006 a 2011. O período da revisão foi restrito propositalmente, visando obter informações recentes sobre as leis ou diretrizes de cada país. Os sites de buscas utilizados foram Cochrane BVS e Pub Med. As palavras-chave utilizadas foram: lei, legislação, bioética, guia de referência e reprodução humana assistida. Adicionalmente, foram identificados e incluídos na pesquisa documentos oficiais relevantes do Estado brasileiro e espanhol (leis e resoluções); e algumas publicações e documentos de organismos e sociedades internacionais, como a Sociedade Europeia de Reprodução Assistida.

A escolha dos países visou principalmente à diversidade. Por isso foram selecionados países de praticamente todos os continentes, com diferentes situações econômicas, sociais, culturais e religiosas. Foram avaliados nove países: Brasil, China, Dinamarca, Egito, Índia, Israel, Itália, África do Sul e Espanha.

Brasil, China, Egito, Índia representam os países governados por guia de referência ou leis não específicas. Dinamarca, Israel, Itália, África do Sul e Espanha são países governados por leis específicas em reprodução assistida (IFFS, 2010). Não foi selecionado nenhum país sem legislação ou guia de referência para este trabalho, devido a dificuldade de informação ou informações divergente sobre o assunto.

Desses países, foram apresentados 14 itens relevantes em relação a funcionamento e normatização da reprodução humana assistida. A religião predominante de cada país foi incluída devido à possível influência que pode ter sobre essas normas. São eles: (1) existência de leis ou guias de referência para 
TRA; (2) religião predominante; (3) número de centros que realizam TRA, (4) existência de cobertura por plano de saúde ou assistência do governo para TRA; (5) necessidade de estado civil específico para realizar TRA e acesso de pessoas solteiras e casais homoafetivos; (6) número de embriōes transferidos; (7) criopreservação; (8) doaçōes; (9) micromanipulação; (10) redução fetal; (11) PGD; (12) seleção de sexo por motivos não médicos; (13) útero de substituição; e (14) status do embrião.

\section{Resultados}

Tabela 1. Regulamentação da reprodução assistida em países com legislação não específica ou guia de referência para reprodução humana assistida

\begin{tabular}{|c|c|c|c|c|}
\hline & Brasil & China & Egito & índia \\
\hline $\begin{array}{l}\text { Religiāo } \\
\text { predominante }\end{array}$ & Catolicismo & Budismo & $\begin{array}{l}\text { Islamismo } \\
\text { (sunitas) }\end{array}$ & Hinduísmo \\
\hline $\begin{array}{l}\text { Número de } \\
\text { centros }\end{array}$ & 150 & $102-300$ & $52-55$ & 500 \\
\hline $\begin{array}{l}\text { Cobertura de } \\
\text { seguro/plano de } \\
\text { saúde e acesso }\end{array}$ & $\begin{array}{l}\text { Não tem } \\
\text { cobertura por } \\
\text { nenhum plano } \\
\text { de saúde. Acesso } \\
\text { público existe, } \\
\text { porém limitado. }\end{array}$ & $\begin{array}{c}\text { Não tem } \\
\text { cobertura por } \\
\text { nenhum plano de } \\
\text { saúde e nem por } \\
\text { políticas públicas. }\end{array}$ & $\begin{array}{c}\text { Não tem } \\
\text { cobertura por } \\
\text { nenhum plano de } \\
\text { saúde e nem por } \\
\text { políticas públicas. }\end{array}$ & $\begin{array}{c}\text { Não tem } \\
\text { cobertura por } \\
\text { nenhum plano de } \\
\text { saúde e nem por } \\
\text { políticas públicas. }\end{array}$ \\
\hline $\begin{array}{l}\text { Estado civil e } \\
\text { orientação sexual }\end{array}$ & $\begin{array}{c}\text { Não é necessário } \\
\text { o casal estar } \\
\text { casado. Pessoas } \\
\text { solteiras e casais } \\
\text { homoafetivos têm } \\
\text { acesso garantido. }\end{array}$ & $\begin{array}{c}\text { É necessário } \\
\text { o casal estar } \\
\text { casado. Não } \\
\text { aceitam casais } \\
\text { homoafetivos }\end{array}$ & $\begin{array}{l}\text { É necessário } \\
\text { o casal estar } \\
\text { casado. Não } \\
\text { aceitam casais } \\
\text { homoafetivos }\end{array}$ & $\begin{array}{l}\text { Não é necessário } \\
\text { estar casado. } \\
\text { Pessoas solteiras } \\
\text { e casais } \\
\text { homoafetivos têm } \\
\text { acesso garantido }\end{array}$ \\
\hline $\begin{array}{l}\text { Número de } \\
\text { embrióes } \\
\text { transferidos }\end{array}$ & $\begin{array}{l}2 \text { embriōes para } \\
\text { mulheres até } \\
35 \text { anos; } 3 \text { para } \\
\text { mulheres de } 36 \text { a } \\
39 \text { anos; } 4 \text { para } \\
\text { mulheres acima } \\
\text { de } 40 \text { anos }\end{array}$ & $\begin{array}{l}2 \text { embriōes para } \\
\text { mulheres até } \\
35 \text { anos; } 3 \text { para } \\
\text { mulheres com } \\
\text { mais de } 36 \text { anos }\end{array}$ & $\begin{array}{l}\text { 2- } 4 \text { embrióes } \\
\text { de acordo com a } \\
\text { idade }\end{array}$ & $\begin{array}{l}\text { No máximo } 3 \\
\text { embriōes. Mais } \\
\text { embriōes só em } \\
\text { circunstâncias } \\
\text { especiais }\end{array}$ \\
\hline
\end{tabular}




\begin{tabular}{|c|c|c|c|c|}
\hline & Brasil & China & Egito & índia \\
\hline Criopreservação & $\begin{array}{c}\text { É permitida } \\
\text { criopreservação } \\
\text { de sêmen, } \\
\text { embrião e oócito. }\end{array}$ & $\begin{array}{c}\text { É permitida } \\
\text { criopreservação } \\
\text { de sêmen, } \\
\text { embrião e oócito. }\end{array}$ & $\begin{array}{c}\text { É permitida } \\
\text { criopreservação } \\
\text { de sêmen, oócito, } \\
\text { embrião. }\end{array}$ & $\begin{array}{c}\text { É permitida } \\
\text { criopreservação } \\
\text { de sêmen oócito, } \\
\text { embrião e } \\
\text { tecido ovariano/ } \\
\text { testicular. }\end{array}$ \\
\hline $\begin{array}{l}\text { Reprodução } \\
\text { póstuma }\end{array}$ & Permitida & Proibida & Proibida & Permitida \\
\hline Doação & $\begin{array}{l}\text { Permitida doação } \\
\text { de sêmen, oócito } \\
\text { e embriāo para } \\
\text { qualquer tipo de } \\
\text { procedimento em } \\
\text { TRA. }\end{array}$ & $\begin{array}{c}\text { Permitida doação } \\
\text { de sêmen, oócito } \\
\text { e embrião para } \\
\text { qualquer tipo de } \\
\text { procedimento em } \\
\text { TRA. }\end{array}$ & $\begin{array}{l}\text { Proibida doação } \\
\text { de sêmen, oócito } \\
\text { e embrião. }\end{array}$ & $\begin{array}{c}\text { Permitida doação } \\
\text { de sêmen, oócito } \\
\text { e embrião para } \\
\text { qualquer tipo de } \\
\text { procedimento em } \\
\text { TRA. }\end{array}$ \\
\hline Redução fetal & Proibida & Permitida & Permitida & Permitida \\
\hline $\begin{array}{l}\text { PGD } \\
\text { (diagnóstico } \\
\text { genético pré } \\
\text { implantacional) }\end{array}$ & Permitido & Proibido & Permitido & Permitido \\
\hline $\begin{array}{l}\text { Útero de } \\
\text { substituiçãao }\end{array}$ & Permitido & Proibido & Proibido & Permitido \\
\hline $\begin{array}{l}\text { Estatus do } \\
\text { embrião }\end{array}$ & $\begin{array}{l}\text { A personalidade } \\
\text { civil começa ao } \\
\text { nascimento com } \\
\text { vida, mas a lei } \\
\text { póe a salvo, desde } \\
\text { a concepção, } \\
\text { o direito do } \\
\text { nascituro. } \\
\text { (Código Civil, } \\
\text { artigo } 2^{\circ}, 2002 \text { ). }\end{array}$ & $\begin{array}{l}14 \text { dias depois da } \\
\text { fecundação }\end{array}$ & $\begin{array}{l}\text { Não é definido. } \\
\text { Há opiniōes } \\
\text { conflitantes entre } \\
\text { opinião pública, } \\
\text { lei e especialistas. }\end{array}$ & $\begin{array}{l}14 \text { dias depois da } \\
\text { fecundação }\end{array}$ \\
\hline $\begin{array}{l}\text { Seleção de sexo } \\
\text { por motivos não } \\
\text { médicos }\end{array}$ & Proibida & Proibida & Proibida & Proibida \\
\hline
\end{tabular}



legislação específica

\begin{tabular}{|c|c|c|c|c|c|}
\hline & Dinamarca & Israel & Itália & África do Sul & Espanha \\
\hline $\begin{array}{l}\text { Religiáo } \\
\text { predominante }\end{array}$ & Protestantes & Judaísmo & Catolicismo & "Cristão" & Catolicismo \\
\hline $\begin{array}{l}\text { Número de } \\
\text { centros }\end{array}$ & $18-22$ & $24-30$ & 360 & $12-15$ & $177-203$ \\
\hline $\begin{array}{l}\text { Cobertura de } \\
\text { seguro/plano de } \\
\text { saúde e acesso }\end{array}$ & $\begin{array}{c}\text { Acesso público. } \\
\text { Governo financia } \\
\text { até } 3 \text { tentativas } \\
\text { de FIV com } \\
\text { medicamentos } \\
\text { pagos }\end{array}$ & $\begin{array}{c}\text { Cobertura } \\
\text { prevista por um } \\
\text { plano nacional } \\
\text { de saúde até a } \\
\text { mulher ter } 2 \\
\text { filhos }\end{array}$ & $\begin{array}{l}\text { Acesso público. } \\
\text { Cobertura por } \\
\text { um plano de } \\
\text { saúde do governo }\end{array}$ & $\begin{array}{l}\text { Subsidiado por } \\
\text { políticas públicas } \\
\text { e instituições } \\
\text { acadêmicas. } \\
\text { A maioria dos } \\
\text { planos de saúde } \\
\text { não cobre TRA e } \\
\text { os que cobrem são } \\
\text { bem limitados. }\end{array}$ & $\begin{array}{c}\text { Cobertura } \\
\text { de qualquer } \\
\text { procedimento por } \\
\text { um plano nacional } \\
\text { de saúde que custeia } \\
\text { cerca de } 30 \% \text { do } \\
\text { tratamento. } \mathrm{O} \\
\text { restante por conta } \\
\text { do paciente. }\end{array}$ \\
\hline $\begin{array}{l}\text { Estado civil } \\
\text { e orientação } \\
\text { sexual }\end{array}$ & $\begin{array}{l}\text { Não é necessário } \\
\text { o casal estar } \\
\text { casado. Pessoas } \\
\text { solteiras e casais } \\
\text { homoafetivos têm } \\
\text { acesso garantido. }\end{array}$ & $\begin{array}{l}\text { Não é necessário } \\
\text { o casal estar } \\
\text { casado;pessoas } \\
\text { solteiras têm } \\
\text { acesso garantido. }\end{array}$ & $\begin{array}{c}\text { Casal com } \\
\text { relacionamento } \\
\text { estável. }\end{array}$ & $\begin{array}{c}\text { Não é necessário } \\
\text { o casal estar } \\
\text { casado. Pessoas } \\
\text { solteiras e casais } \\
\text { homoafetivos têm } \\
\text { acesso garantido }\end{array}$ & $\begin{array}{l}\text { Não é necessário o } \\
\text { casal estar casado. } \\
\text { Pessoas solteiras e } \\
\text { casais homoafetivos } \\
\text { têm acesso garantido }\end{array}$ \\
\hline $\begin{array}{l}\text { Número de } \\
\text { embrióes } \\
\text { transferidos }\end{array}$ & $\begin{array}{c}1 \text { embrião para } \\
\text { mulheres até } 35 \\
\text { anos na primeira } \\
\text { e segunda } \\
\text { tentativa. Mais } \\
\text { que um embriāo } \\
\text { em tentativas } \\
\text { subsequentes. }\end{array}$ & $\begin{array}{l}\text { No máximo } 2 \\
\text { embriōes se a } \\
\text { mulher for maior } \\
\text { que } 35 \text { anos. }\end{array}$ & $\begin{array}{l}\text { No máximo } 3 \\
\text { oócitos podem } \\
\text { ser fertilizados ao } \\
\text { mesmo tempo. } \\
\text { Todos devem ser } \\
\text { transferidos }\end{array}$ & $\begin{array}{c}\text { Não é } \\
\text { especificado. }\end{array}$ & $\begin{array}{c}\text { No máximo } 3 \\
\text { embriōes. Não é } \\
\text { especificado por } \\
\text { idade. }\end{array}$ \\
\hline Criopreservação & $\begin{array}{c}\text { Permitida a } \\
\text { criopreservação } \\
\text { de sêmen, oócito, } \\
\text { embrião e tecido } \\
\text { ovariano / } \\
\text { testicular. }\end{array}$ & $\begin{array}{c}\text { Permitida } \\
\text { criopreservação } \\
\text { de sêmen, oócito, } \\
\text { embriāo e tecido } \\
\text { ovariano e } \\
\text { testicular. }\end{array}$ & $\begin{array}{c}\text { Permitida } \\
\text { criopreservação } \\
\text { de sêmen, oócito } \\
\text { e tecido ovariano } \\
\text { / testicular. } \\
\text { É proibida a } \\
\text { criopreservação } \\
\text { de embriāo. }\end{array}$ & $\begin{array}{c}\text { Permitida } \\
\text { criopreservação } \\
\text { de sêmen, oócito } \\
\text { e tecido ovariano } \\
\text { / testicular. } \\
\text { Embrião não é } \\
\text { mencionado. }\end{array}$ & $\begin{array}{c}\text { É permitida a } \\
\text { criopreservação } \\
\text { de sêmen, oócito, } \\
\text { embrião e tecido } \\
\text { ovariano/testicular }\end{array}$ \\
\hline $\begin{array}{l}\text { Reprodução } \\
\text { póstuma }\end{array}$ & Proibido & Permitido & Proibido & Permitido & Permitido \\
\hline
\end{tabular}




\begin{tabular}{|c|c|c|c|c|c|}
\hline & Dinamarca & Israel & Itália & África do Sul & Espanha \\
\hline Doação & $\begin{array}{c}\text { Permitida } \\
\text { doação de sêmen } \\
\text { para qualquer } \\
\text { procedimento em } \\
\text { TRA. Oócito não } \\
\text { foi mencionado. } \\
\text { Não é permitida } \\
\text { doação de embrião }\end{array}$ & $\begin{array}{l}\text { Permitida doação } \\
\text { de sêmen e } \\
\text { oócito. Mas é } \\
\text { proibida a doação } \\
\text { de embrião. }\end{array}$ & $\begin{array}{l}\text { Proibida doação } \\
\text { de oócito, sêmen } \\
\text { e embriāo. }\end{array}$ & $\begin{array}{l}\text { Permitida doação } \\
\text { de sêmen, oócito } \\
\text { e embrião para } \\
\text { qualquer tipo de } \\
\text { procedimento em } \\
\text { TRA. }\end{array}$ & $\begin{array}{c}\text { Permitida doação } \\
\text { de sêmen, oócito } \\
\text { e embrião para } \\
\text { qualquer tipo de } \\
\text { procedimento em } \\
\text { TRA. }\end{array}$ \\
\hline Redução fetal & Permitida & Permitida & Permitida & $\begin{array}{c}\text { Não é } \\
\text { mencionado }\end{array}$ & Não é permitida \\
\hline $\begin{array}{l}\text { PGD } \\
\text { (diagnóstico } \\
\text { genético pré } \\
\text { implantacional) }\end{array}$ & Permitido & Permitido & Permitido & $\begin{array}{l}\text { Não é previsto } \\
\text { no estatuto, mas } \\
\text { procedimento é } \\
\text { realizado. }\end{array}$ & Permitido \\
\hline $\begin{array}{l}\text { Útero de } \\
\text { substituição }\end{array}$ & Proibido & Permitido & Proibido & Permitido & Proibido \\
\hline $\begin{array}{l}\text { Status do } \\
\text { embriáo }\end{array}$ & $\begin{array}{l}14 \text { dias depois da } \\
\text { fecundação }\end{array}$ & $\begin{array}{l}\text { Não é definido } \\
\text { por lei. Porém há } \\
\text { forte concepção } \\
\text { cultural e } \\
\text { religiosa que a } \\
\text { vida começa } 40 \\
\text { dias depois da } \\
\text { fecundação. }\end{array}$ & $\begin{array}{c}\text { Já é uma pessoa } \\
\text { desde o momento } \\
\text { que o óvulo } \\
\text { entrou em } \\
\text { contato com o } \\
\text { espermatozoide } \\
\text { (2007) }\end{array}$ & Não é definido & $\begin{array}{c}\text { O embrião é } \\
\text { considerado uma } \\
\text { pessoa. }\end{array}$ \\
\hline $\begin{array}{l}\text { Seleção de sexo } \\
\text { por motivos não } \\
\text { médicos }\end{array}$ & Proibido & Permitido & Proibido & Proibido & Proibido \\
\hline
\end{tabular}

\section{Discussão}

Em relação à oferta de tratamento em reprodução assistida, países desenvolvidos como Itália e Espanha (com exceção da Dinamarca) e países em desenvolvimento, mas em amplo crescimento, como é o caso de Brasil, China e Índia, apresentam pelo menos cem centros que oferecem tratamentos em reprodução assistida. Esse fato é relevante, pois está diretamente relacionado à economia desses países, pois são necessários investimentos tanto na infraestrutura e tecnologia como na formação de mão de obra especializada para realizar tais procedimentos. 
Perdurando esse raciocínio, em alguns países o governo oferece ou subsidia tratamentos em reprodução assistida - caso da Dinamarca, Itália e Espanha. Nesses países há incentivo do governo para os casais procriarem devido ao baixo crescimento demográfico dessas populaçôes. Em Israel, o tratamento é oferecido pelo governo até a mulher gestar pelo menos dois filhos. Essa facilidade tem um motivo religioso: o judaísmo incentiva fortemente o casal a gerar descendentes.

Em relação ao estado civil e orientação sexual específica para utilização de técnicas de reprodução assistida, Egito e Itália são restritivos. Ambos não permitem que pessoas solteiras e casais homoafetivos utilizem TRA. Essa impossibilidade está diretamente ligada à religião, islamismo e catolicismo, que são muito fortes nesses países e têm opiniōes conservadoras em relação a reprodução assistida e novas composições de família (HOWARD; CROCKIN, 2000). Os demais países têm um entendimento que qualquer pessoa maior de idade e capaz pode realizar tratamento de reprodução assistida, se assim desejar.

Foi observado que praticamente todos os países envolvidos neste estudo delimitam, de acordo com a idade da mulher, o número de embriōes a serem transferidos. A única exceção é a África do Sul, onde não há essa limitação. A redução de embriōes transferidos tem se tornado uma tendência mundial, cujo objetivo é evitar gestações múltiplas, diminuindo o risco materno e procedimentos de redução embrionária (ASRM, 2008). Cabe destacar a Dinamarca, que prevê transferências de apenas um embrião para pacientes com menos de 35 anos.

A criopreservação de gametas e embriōes é um procedimento bem aceito na reprodução assistida. Entre os países que fazem parte desta pesquisa, praticamente todos autorizam a criopreservação de sêmen, oócito e embriōes, com exceção da Itália, onde não se permite a criopreservação de embriōes, assim como todos os embriōes fertilizados (no máximo três) devem ser transferidos para o útero materno. Nesse caso, ocorre uma influência religiosa muito grande, pois o catolicismo acredita que o congelamento provoca injúrias ao embrião e consequentemente a uma vida humana (DONUM VITAE, 1982). Dessa forma, todo o tratamento deve ser realizado com o objetivo de não gerar embriōes excedentes. Essa restrição, sem dúvida, é a maior limitação nos tratamentos de reprodução assistida na Itália, gerando diversas consequências. Ragni e colaboradores, em 2005, realizaram estudo mostrando que a partir de 2004 (ano que entrou em vigor a lei que regulamenta a reprodução assistida na 
Itália) houve diminuição das taxas de gravidez, aumento das taxas de gestações múltiplas e turismo reprodutivo.

Em relação às doações, Dinamarca, Israel (ambos proíbem doações de embriões), Egito e Itália (ambos proíbem qualquer tipo de doação) são restritivos a essa prática. No Egito, Israel e Itália, acredita-se que tal limitação tem a ver com a influência religiosa. $\mathrm{O}$ islamismo, religião predominante no Egito, condena expressamente as doações de gametas e embriōes, inclusive o útero de substituição e reprodução póstuma (SCHENKER, 2005). As doações são um ponto muito delicado para o islamismo. As Escrituras Sagradas islâmicas impedem claramente modos alternativos de formação de família, como as doações de gametas e embriōes, incluindo adoção. Isso porque as crianças teriam uma linhagem desconhecida, e se muito diferentes fisicamente dos pais, passariam a imagem de adultério. $\mathrm{O}$ adultério é uma questão que tem extremo valor para essa sociedade, e a reprodução póstuma é expressamente proibida por esse motivo (INHORN, FAKIH, 2000). Em Israel (judaísmo), também se relacionam as doaçōes de gametas e embriōes com adultério. Já o catolicismo, religião predominante na Itália, condena as doações por serem um ato dissociado do casamento e do ato sexual, assim como todo procedimento em reprodução assistida (DONUM VITAE, 1982). Na Dinamarca, não é provável que a proibição de doação de embrião venha de um fundo religioso. O protestantismo, religião predominante no país, considera o embriāo um ser que está em desenvolvimento gradual, logo tem direito à vida. Dessa forma, a doação de embrião seria aceitável como uma forma de "mal menor", evitando assim o descarte e abandono de embriōes já formados (CAMBIAGHI, 2010).

A redução fetal é um procedimento controverso, porém muito utilizado em caso de gestação múltipla. Entre os países participantes desta pesquisa, somente o Brasil faz essa proibição. Essa restrição se dá porque no Brasil o aborto não é permitido (DECRETO-LEI no 2.848, de 07/12/1940 - Código Penal Brasileiro). De uma forma geral, a redução fetal e o aborto estão associados. Nos países onde é permitido o aborto, geralmente também se permite a redução fetal. Destaque para Itália, que proíbe congelamento porque causaria injúrias ao embriāo, mas permite o aborto e a redução fetal (IFFS, 2010).

Procedimentos de diagnóstico genético pré-implantacional (PGD) não são permitidos na China e na Itália, mas os motivos da proibição são bem diferentes. A China é um país cujo governo exerce grande controle da natalidade, permitindo 
que cada casal tenha apenas um filho. Sendo assim, a preferência dos pais pelo filho de sexo masculino é uma tradição profundamente arraigada, desde a idade feudal. No filho homem, concentra-se a responsabilidade de manter os pais quando idosos. Portanto, a proibição do PGD ocorreu por ser utilizado de maneira indiscriminada para a seleção de sexo (IFFS, 2010). Já na Itália, mais uma vez a proibição tem um provável caráter religioso. Segundo a religião católica, o filho é uma dádiva na vida do casal. Portanto, este deve cuidar e amar essa criança, independentemente de doenças ou malformações congênitas, não justificando, assim, o uso de PGD para detectar qualquer tipo de anomalias (DONUM VITAE, 1987).

Já em Israel, o PGD é utilizado para detectar anomalias genéticas, mas também para a seleção de sexo por motivos não médicos. O judaísmo incentiva os casais a terem pelo menos um casal de filhos. Devido à importância que os judeus dão a esse balanço familiar, a sexagem embrionária é aceitável, sendo inclusive incentivada entre os casais (SCHENKER, 2008).

O status do embrião é o quesito mais controverso entre os países pesquisados. No Brasil, de acordo com o Código Civil Brasileiro, em seu artigo 2o, a personalidade civil começa ao nascimento com vida. Porém a lei põe a salvo o direito do nascituro desde o momento da concepção. Inclusive, o DecretoLei no 2.848, de 07/12/1940 (Código Penal Brasileiro) condena a prática do aborto. Para questões de documento de óbito, há obrigatoriedade de declaração e registro de óbito ou perdas fetais para gestações com duração mínima de 20 semanas ou cujo peso e estatura do concepto sejam no mínimo de $500 \mathrm{~g}$ e $25 \mathrm{~cm}$, respectivamente, sendo facultativo para aqueles abaixo desse valor (CFM, 2005).

$\mathrm{Na}$ China, Dinamarca e Índia, o embriāo já pode ser considerado vida humana após 14 dias da fecundação, momento esse que coincide com o atraso da menstruação e a mulher pode supor a gravidez. Espanha e Itália são mais conservadoras nesse quesito e consideram que o embrião é uma vida humana no momento em que ele se forma. Neste caso, pode ser que ocorra, mais uma vez, influência religiosa. O documento Donum Vitae tem como proposta dar orientação em conformidade com os princípios da moral católica em relação às técnicas biomédicas que manipulam a fase inicial da vida humana e os processos de procriação. O documento explicita através dessa passagem o momento de início da vida humana. 
Desde a fecundação, tem início a aventura de uma vida humana, cujas grandes ca-

pacidades exigem, cada uma, tempo para organizar-se e para encontrar-se prontas a agir. Esta doutrina permanece válida e, além disso, é confirmada - se isso fosse necessário - pelas recentes aquisições da biologia humana, que reconhece que no zigoto derivante da fecundação já está constituída a identidade biológica de um novo indivíduo humano (DONUM VITAE, 1974).

A principal limitação desta pesquisa ocorreu em consequência da diversidade dos países estudados. Assim, não foi possível utilizar legislação ou guia de referência específico de cada país em língua pátria para obtenção de informações sobre a regulamentação da reprodução assistida. Por consequência, não foi viável expor de maneira aprofundada o funcionamento da reprodução assistida em cada país. Entretanto, a heterogeneidade dos países pesquisados, ainda assim, configura uma vantagem neste estudo, pois dessa forma as diferenças socioeconômicas, culturais e religiosas puderam ser observadas e discutidas.

\section{Conclusão}

Desde o surgimento dos TRA, é visível a evolução não só da tecnologia dos tratamentos, mas também de mecanismos reguladores para sua utilização. É crescente o número de países que utilizam leis ou guias de referência para regulamentação da reprodução assistida. Tal fato constitui um avanço para os pacientes e para os profissionais de saúde envolvidos nessa especialidade médica.

Observou-se neste estudo uma influência muito grande de valores religiosos na formulação de legislações e guias de referência em alguns países analisados, como por exemplo, Itália, Israel e Egito. A Itália, sem dúvida é o país mais restritivo. Devido a isso, a lei Italiana vem sendo muito discutida e criticada por especialistas dentro e fora do país (RAGNI et al., 2005).

Existe grande variação entre as nações sobre que é eticamente aceitável em TRA. No entanto, não há dados sofisticados que permitam uma comparação em detalhes dos diversos países e suas situaçôes legislativas distintas. Dessa forma, provavelmente nunca será possível determinar o efeito dos regulamentos ou orientações, ou a falta deles, sobre a evolução clínica de programas de reprodução assistida.

A formulação das legislações está profundamente enraizada na cultura de um a nação. Por esse motivo, provavelmente nunca existirá um consenso mundial sobre a licitude ética dos procedimentos realizados. ${ }^{1}$ 


\section{Referências}

AMERICAN SOCIETY FOR REPRODUCTIVE MEDICINE. Encouraging patientdriven single-embryo transfer. Fertility and Sterility, v. 90, p. 1266-8, 2008.

BRANDON, J. et al. The social implications of embryo cryopreservation. Fertility and Sterility, v. 84, n. 4, p. 823-832, 2005.

BRASIL, F.R. A sociedade e a lei civil: o eterno processo de atualização. Set, 2004. Disponível em: $<$ http://www.direitonet.com.br/artigos/exibir/1736/A-sociedade-e-a-leicivil-o-eterno-processo-de-atualizacao>. Acesso em: 29 jun. 2011.

BRASIL. Ministério da Justiça. Código Civil Brasileiro de 2002. Disponível em <http:// www.cmc.pr.gov.br/down/ccivil.pdf >. Acesso em: 10 out. 2011

BRASIL. Lei no 2.848, de 07 dez 1940; alterado pela lei no 9777 em 26 dez 1998. Código Penal Brasileiro. Artigo 124, parágrafo único. Disponível em: <http://www.oas.org/ juridico/mla/pt/bra/pt_bra-int-text-cp.pdf>

BRASIL. Lei no 11.105, de 24 de março de 2005. Dispõe sobre a Política Nacional de Biossegurança. Diário Oficial [da] República Federativa do Brasil, Brasília, DF. Disponível em <http://www.planalto.gov.br/ccivil_03/_Ato2004-2006/2005/lei/L11105.htm>. Acesso em: 18 mar. 2011.

BRASIL. Resolução CFM no 1.957/2010, de 06 de janeiro de 2011. Diário Oficial [da] República Federativa do Brasil, Brasília, DF, Seção I, p. 79. Disponível em <http://www. portalmedico.org.br/resolucoes/CFM/2010/1957_2010.htm >. Acesso em: 18 mar. 2011.

BRASIL. Lei no. 9.263, de 12 de janeiro de 1996. Lei do Planejamento Familiar. Diário Oficial [da] República Federativa do Brasil, Brasília, DF Disponível em < http://www. unifesp.br/dgineco/planfamiliar/lei.htm>. Acesso em: 10 de out. 2011.

CAMBIAGHI, S.A. Os tratamentos de fertilização e as religiōes. O permitido e o proibido. São Paulo: Vida Press, 2010.

CONSELHO FEDERAL DE MEDICINA. Resolução no 1.779, de 05 de dezembro de 2005. Diário Oficial [da] República Federativa do Brasil, Brasília, DF. Seão I, p. 121. Disponível em:<http://www.portalmedico.org.br/resolucoes/cfm/2005/1779_2005.htm.>Acesso em: 12 out. 2011.

DONUM VITAE. João Paulo II, Exort. Apost. Familiaris consortio, 14: AAS 74 (1982) 96. Disponível em: http://www.vatican.va/roman_curia/congregations/cfaith/documents/ rc_con_cfaith_doc_19870222_respect-for-human-life_po.html > Acesso em: 23 abr. 2011. DONUM VITAE. Sagrada Congregação para a Doutrina da Fé. Declaração sobre o aborto provocado, 12-13: AAS 66 (1974), 738. Disponível em: <http://www.vatican.va/roman_ 
curia/congregations/cfaith/documents/rc_con_cfaith_doc_19870222_respect-for-human-

life_po.html> Acesso em : 23 abr. 2011.

DONUM VITAE. Santa Sé. Carta dos direitos da família, 4: L’Osservatore Romano, ed. diária, 25 de novembro de 1983. Disponível em: <http://www.vatican.va/roman_curia/ congregations/cfaith/documents/rc_con_cfaith_doc_19870222_respect-for-human-life_ po.html > Acesso em: 23 abr. 2011.

ESPANHA. Ley 14/2006, de 26 de mayo, sobre técnicas de reproducción humana asistida. Espanha, 2006. Disponível em <http://noticias.juridicas.com/base_datos/Admin/1142006.html 19/3/2011> Acesso em: 23 abr. 2011.

HOWARD W.J.J.; CROCKIN, L.J.D. On assisted reproduction, religion, and civil law. Fertility and Sterility, v. 73, n. 3, p. 447-452, 2000.

INHORN, C.M.; FAKIH, M.H. Arab Americans, African Americans, and infertility: barriers to reproduction and medical care. Fertility and Sterility, v.85, p. 844-852, 2006.

INTERNATIONAL FEDERATION OF FERTILITY SOCIETIES SURVEILLANCE. Preface. Fertility and Sterility, v. 87, p. 68-140, 2007.

INTERNATIONAL FEDERATION OF FERTILITY SOCIETIES SURVEILLANCE. Preface. Fertility and Sterility, v. 95, p. 95-491, 2011.

RAGNI, G. et al. The 2004 Italian legislation regulating assisted reproduction technology: a multicentre survey on the results of IVF cycles. Human Reproduction, v. 20, n. 8, p. 22242228, 2005.

SABBATINI, R. O caso dos embriōes congelados. 1998. Jornal Correio Popular, Campinas. Disponível em: <http://epub.org.br/svol/corr9696 > Acesso em: 23 abr. 2011.

SCHENKER, J. Assisted reproductive practice: religious Perspectives. RBMOnline, v. 10, p. 310-319, 2005. Disponível em : <http://www.ncbi.nlm.nih.gov/pubmed/15820035>

SCHENKER, J. Assisted reproductive technology: perspectives in Halakha (Jewish religious law). RBMOnline, v. 17, p. 17-24, 2008.

STEPTOE, P.C.; EDWARDS, R.G. Birth after the reimplantation of a human embryo. Lancet, v. 2, p. 312-366, 1978.

THEETHICSCOMMITTEEOFTHEAMERICANSOCIETYFORREPRODUCTIVE MEDICINE. Sex selection and preimplantation genetic diagnosis. Fertility and Sterility, v. 72, n. 4, 1999.

THEETHICSCOMMITTEEOFTHEAMERICANSOCIETYFORREPRODUCTIVE MEDICINE. Family members as gamete donors and surrogates. Fertility and Sterility, v. 80, n. 5, 2003. 
THEETHICSCOMMITTEEOFTHEAMERICANSOCIETYFORREPRODUCTIVE MEDICINE. Fertility and Sterility, v. 82, supl. 1, September 2004.

THE ETHICS COMMITTEE OF THE AMERICAN SOCIETY FOR REPRODUCTIVE MEDICINE. Donating spare embryos for stem cell research. Fertility and Sterility, v. 91, n. 3, March 2009.

TOSCHI, A. et al. Consequences of a restrictive art law on clinical outcome. Fertility and sterility, v. 86, issue 3, suppl., p. S70, 2006.

\section{Nota}

${ }^{1}$ T.L Henriques participou da escolha do tema, desenho do estudo, revisão bibliográfica, interpretação dos dados e redação do artigo. R.A.H. Holanda participou da revisão bibliográfica, interpretação dos dados e aprovação final da versão a ser publicada. 
Bioethics in assisted human reproduction: influence of socio-economic and cultural aspects of the formulation of laws and reference guides factors in Brazil and other nations

In 1978 the first baby generated by in vitro fertilization (IVF) was born. From there, assisted reproduction techniques (ART) began to develop and become a clinical reality in the treatment of infertility. However, assisted reproduction has made great controversies of moral and ethical character arise. Because of these differences, some countries have chosen to regulate assisted reproduction through specific legislation or guidelines. This study aimed to compare laws or references in assisted human reproduction guides from different countries, show differences from the norms in ART, taking into account social, financial, religious and cultural aspects of 9 countries: Brazil, China, Egypt, India ( countries with guidelines ) and Denmark, Israel, Italy, South Africa and Spain (countries with specific legislation ). A review was made in the literature between 2006 and 2011. The search sites used were: VHL Cochrane, PUB MED. Some important documents relating to the matter were added to the survey. The researched items were: existence of laws or guidelines for ART, predominant religion in each country, the number of centers performing ART, coverage by a health plan or government assistance to ART, marital status and need for access for unmarried people and homosexual couples, number of transferred embryos, cryopreservation and donation of gametes and embryos, embryo reduction, PGD, sex selection for non-medical reasons, uterus replacement; status of the embryo. We found large differences between countries, many of which are determined by religion.

> Key words: low, legislation, guidelines, bioethics, assisted reproduction. 